\title{
Learning Content Management Systems
}

\author{
Tache JURUBESCU \\ Ministry of Defense, Bucharest, România \\ tache26@yahoo.com
}

\begin{abstract}
The paper explains the evolution of e-Learning and related concepts and tools and its connection with other concepts such as Knowledge Management, Human Resources Management, Enterprise Resource Planning, and Information Technology. The paper also distinguished Learning Content Management Systems from Learning Management Systems and Content Management Systems used for general web-based content. The newest Learning Content Management System, very expensive and yet very little implemented is one of the best tools that helps us to cope with the realities of the $21^{\text {st }}$ Century in what learning concerns. The debates over how beneficial one or another system is for an organization, can be driven by costs involved, efficiency envisaged, and availability of the product on the market.
\end{abstract}

Keywords: Knowledge Management (KM), Human Resources Management (HRM), Enterprise Resource Planning (ERP), e-Learning, Learning Management Systems (LMS), Content Management Systems (CMS), Learning Content Management Systems (LCMS), Information Technology (IT).

\section{I}

\section{ntroduction}

The need of doing things better and better, having more experts in various domains of society of the 21st Century introduced aggressively new tools of learning. Instead of classical classrooms, during the last decades virtual classrooms, invaded worldwide our teaching systems. The power of Internet and its almost unlimited possibility of connecting people determined a "boom" of communication from a simple letter to banking, trading, learning, conferencing, not to mention space exploring, satellites which make that easier, etc. Virtual classrooms seen as web conferencing, provide the means to conduct a live class over the Internet in real time, like a lecture. There is typically a whiteboard space that can display any document from any participant's computer, and can allow datasharing and direct input from participants. Some tools use standard telephone conferencing for the audio, some use voice over internet protocol (VoIP), some include video as well. Usually provided are instant text messaging among the participants and breakout rooms for sub-groupings.

e-Learning become part of our day to day lives. Learning Management Systems (LMS), and Learning Content Management System (LCMS) are more and more usual words, and products on the market, next to Human Resources Information Systems (HRIS) and Enterprise Resource Planning (ERP) systems to conduct skill gap analysis, performance tracking, competency mapping [1]

\section{e-Learning}

Form the '60s e-Learning developed to cover now almost 50 percent of training. Starting with computer-based instruction (CBI), and computer-based training (CBT), the distribution in the '80s of learning material on CDs, the introduction in the '90s of World Wide Web opened new possibilities, being nowadays the primary delivery medium. Distance education has become an essential part of formal education, from elementary to postsecondary. Web conferencing has become also an important way for organizations to collaborate, hold cost-effective meetings, and markets products and services. e-learning (online learning or Web-based training) can take many forms: from a simple Web page or e-mail discussion group, to video, audio, and elaborate machine or social interaction simulations. It can be synchronous (at the same time), as in chat rooms and Web conferencing, or asynchronous (not at the same time), as in e-mail and stand-alone, self-directed learning. 
When the e-Learning market initially formed [2], it became a covering umbrella for a multitude of market segments well established like computer-based training content providers, and training managements systems, and new segments such as web-based training and virtual classrooms. All of these became aspects of the e-Learning market.

Speaking from a technology point of view, this resulted in hundreds of mainly niche vendors selling very different kinds of products under the e-Learning banner. Over the last years, the market has changed significantly. Now vendors forgot e-Learning and talk about e-Learning suites. e-Learning suites integrate components from the principal e-Learning segments, such as learning management system, learning content management system, content authoring tool, and collaboration tools including virtual classroom functionality.

\section{Learning Management Systems}

Since the eary days of e-Learning, Learning Management Systems (LMS) have been one of the key driving sectors of the market. As a concept, learning management is an evolution of the processes and systems that schools and companies developed to register students in courses and keep track of student records. The learning options of students or employees diversified very much, so they can take now courses online, as part of a formal curriculum or to fulfill certification requirements, exchange e-mails with a mentor on a regular basis, collaborate with other learners in on-line meetings and via e-mail, take courses both in their company or institution, or off-site at another company or institution, perform an Internet search for information, withdraw a book from a library, etc. A learning management system enables and keeps records for all of these activities. The system can present a catalog of both online and classroom learning opportunities to the students, launch e-learning courses, allow participants to sign up for these opportunities when convenient, allow administrators to schedule the courses and assign instructors, facilities, and equipment to a course, provide the means to keep track of course attendance and results, maintain a database of courses taken and results for each individual in the organization.

For most of the e-Learning providers the real problem is the procurement of a state-of-thearts LMS. The landscape around training and learning is also problematic and includes big changes in Human Resources (HR), Enterprise Resource Planning (ERP), or HR IT systems with organizational restructuring, making even more difficult the approval of an appropriate budget. The lack of expert LMS knowledge comes as additional challenge in the procurement and implementation of such projects. Companies are generally starting from scratch gathering information, attending conferences and presentations. So far, training functions have operated without much knowledge of IT systems, and IT does not know much about the business and processes of training, except for IT training. Introducing an LMS project can be delayed sometimes because of these difficulties. The need for something to manage learning process and all modes of learning is strong and not dealt with by training administration components of ERP or HR suites.

On the other hand, the rapid changing market, coupled with the change in the products themselves, make the LMS market even more diverse. Now, designers have to rearchitect the system to allow learners selfservice web access, and a full-based administration and management. Some developers evolve the products into "Human Capital Management System", and this differentiates them from straight LMS, and increase competition with the HR systems vendors. Other new areas for differentiation outside core LMS functionality are the increased interest in LCMS and closer integration with Knowledge Management (KM).

\section{Learning Content Management Systems}

Learning Content Management System represents a multi-user environment where learning developers can create, store, reuse, manage and deliver digital learning content from a central object repository [3]. The 
terms LMS and LCMS are not mutually exclusive. Most LCMS provide basic LMS functionality, and many LMS include some aspects of content management as well. Some vendors provide everything in a single package. The modern content management system was invented in late ' 90 s by an Internet news publishing company. Web publishing is a fairly complex process. First, the author has to submit an article, written using tools that are intuitive for a non-technical writer to use. Before publishing, an editor needs to review the article and make changes, possibly even sending the article back to the author for further editing. Multiple versions of the document could be flying back and forth among the author, and editor. Once the content is finalized, it needs to be put into the layout in which it will appear on the site. The editor may decide to add related links. Somebody needs to decide where on the site the article will go. And once it's all done, somebody else has to post the article to the public web site.

The only solution to this kind of problem is to automate any part of the process that doesn't require human judgment. Writers can type their articles directly into the publishing system using a web-based text editor. When the article is submitted online, it can instantly be made available to the editor, who also could receive an email alert that a new article is ready for review. The editor can then make changes online and click the "submit" button, which sends it on to the copy-editor. Since most articles are generally presented in one of a small handful of well-established layouts, the editor need only choose the appropriate layout template and the article will automatically be formatted appropriately. Likewise, the editor can click a few buttons to choose where on the site the article will be published and when it will go up, and the system will take care of the rest. No further human intervention is necessary.

In this new system, most of the issues of paper passing, logistics, and scheduling are handled by the software. Editors can focus on editing. Writers can focus on writing. Programmers and graphic designers aren't really needed for the production of typical articles, and when they are needed they are only handling the aspects of the article that are unique. Being said that, don't think the CMS is writing a good content for the writer, but it does clear away most of the clutter that distracts the writer from the task of writing good content. This tool proved to be valuable to anyone who has large quantities of content that need to be published and kept up-to-date online, whether they are news sites, ecommerce sites, or corporate intranets.

Up until recently, CMS's were not being used in online learning because they are very expensive. In order to justify the costs, the system users have to be creating and maintaining a large enough volume of content that the system will pay for itself through the incremental savings of time and money required to produce each content item. Unfortunately, the needs of a CMS for Internet news publishing and the needs of a CMS for e-learning are not quite the same. Both the end product and the workflow process that produces it are unique to e-learning. Before we can benefit from these innovations, we have to think through those differences carefully. We need to come up with a learning content management system, or LCMS.

The primary role of LCMS is to manage digital assets used for developing learning products. These systems provide a database called a learning content object repository that will save work done by authors of courses as learning objects, which can be accessed by the same or other authors to develop new learning, workflow information for convenient updating of content, course authoring capability, collaboration tools to enable course authors and learners to work together, some basic LMS capability, ways to create and administer tests and quizzes.

There are also course management systems (CMS) which combine elements of both LMS and LCMS, but these are aimed primarily at formal education-particularly postsecondary - and have special features for that market. Some vendors of these systems call them LCMS. 


\section{Conclusion}

The Learning Content Management Systems segment allow organizations to leverage one application to educate a variety of students: employees, partners, suppliers, and customers. An Learning Content Management System is an valuable tool that compresses the time required to develop learning content. Through the use of learning objects, the technology delivers targeted learning, and shortens a learner's time to proficiency. The net result of this is increased organizational productivity [4].

\section{References}

[1] Don McIntosh, "E-Learning and Learning Management”, Technology Evaluation Centers, 3 September 2008 (originally pub- lished January 13, 2006),

www.technologyevaluation.com/research/arti cles/learning-management/E-learning and

Learning Management.mht

[2]David Wilson, "E-Learning suites or not", in E-Learning suites, elearnity, June 2003

[3] Bryan Chapman, "e-Learning for the Enterprise: why Learning Content Management matters most?", from Brandon-Hal.com, Your Guide to e-Learning

[4] Michael Brennan, Susan Funke, and Cushing Anderson, "The Learning Content Management Systems - A new eLearning marketsegment emerges ", An IDC White Paper, IDC Analyze the Future, 2001 at www.idc.com. 